\title{
Perceptions of pharmacy students regarding language of instruction in health education
}

\author{
Tabinda hasan ${ }^{1}$, Khadyja abdalaziz $^{2}$ \\ ${ }^{I}$ (Research scholar,Faculty of medicine,SVS University, India) \\ ${ }^{2}$ (faculty of applied health sciences, jazan university,Saudi Arabia)
}

\begin{abstract}
The Arab world is a gateway between the West and the East and a land of ancient cultures and conflicts. Arabs are living in confusing times while attempting to build modern civilizations based on ancient traditions. Presently, Arab students stand at crossroads regarding the medium of instruction in health education (English-versus-Arabic). Federal policy pursues proficiency in English and accredits English authored text-books while native beneficiary population still faces considerable linguistic inertia and prefers Arabic. In countries like Saudi Arabia, where tutor population is majorly fractioned into Arabic and non-Arabic speakers, the perception of students is pivotal in assessing the role of language in achievement of learning objectives. This study explores Arab students linguistic preferences and attitudes in pharmacy education through administering a semi structured questionnaire. Survey based data suggests that a majority of Arab pharmacy students still prefer Arabic as the predominant medium of classroom instruction. The key underlining factor for such attitudes is the harmony between 'thinking and speaking' that is created with the use of 'familiar 'language.
\end{abstract}

$\underline{\text { Keywords - pharmacy, students, language, education }}$

\section{INTRODUCTION}

The Arab world is a gateway between the West and the East and a land of ancient cultures and conflicts. Arabs are living in confusing times while attempting to build modern civilizations based on ancient traditions. Presently, Arabs stand at crossroads regarding the medium of instruction in health education (English-versus-Arabic). Federal policy pursues proficiency in English and accredits English authored text-books while native beneficiary population still faces considerable linguistic inertia and prefers Arabic. In countries like SaudiArabia, where Arabic is widely used for all conventional everyday purposes and the tutor population is majorly fractioned into Arabic and non-Arabic speakers, the perception of students is pivotal in assessing the role of language in achievement of learning objectives. This study explores Arab student's linguistic preferences and attitudes regarding Pharmacy education.

\section{METHODS}

A semi structured questionnaire with open and close ended questions ascertained female student's opinions regarding language used during class-room instructions in a pharmacy college of Saudi Arabia during 2010 to 2011 academic session. The objective of the survey was to determine the role of language as a crucial factor in determining assimilation of core knowledge and achievement of learning objectives. 90 female students of second year pharmacy course took part in the study and described their linguist choices and the rationale behind those choices; (Arabic only vs English only vs Arabic and English both) Data analysis was done using basic descriptive statistics with confidence interval of $95 \%$ and $p$ value of less than .05 was considered significant.

\section{RESULTS}

Many Arab pharmacy students still prefer their native language as the predominant medium of classroom instruction.(Table 1 and Fig. 1)

Majority of students; $\mathrm{n}=40(44 \%)$ preferred use of "Arabic only" during didactic lectures. (Rationale:-English was an unfamiliar 'alien' language that obstructed understanding of important concepts.)

Some of the students; $n=33(37 \%)$ preferred "Bi-lingual approach".(Rationale:-It promoted understanding of scientific concepts as well language enrichment)

The least number of students; $\mathrm{n}=17(19 \%)$ preferred "Exclusive use of English" (Rationale:-Language is learned with application rather than evasion)

ISSN: 2250-3013

www.iosrphr.org

429 | P a g e 
Table 1- Female students perceptions regarding the medium of classroom instruction in pharmacy education; $\mathrm{N}=90$, 2nd year, academic session 2010-2011, Pharmacy college, Jazan University, KSA

\begin{tabular}{|l|l|l|l|l|}
\hline $\begin{array}{l}\text { Preferred } \\
\text { language }\end{array}$ & $\begin{array}{l}\text { Number } \\
(\mathrm{N}=90)\end{array}$ & Percentage & Rationale & P value \\
\hline Arabic & 40 & $44 \%$ & $\begin{array}{l}\text { English is an } \\
\text { unfamiliar 'alien' } \\
\text { language that } \\
\text { obstructs } \\
\text { understanding of } \\
\text { concepts. }\end{array}$ & $\begin{array}{l}\text { Arabic only } \\
\text { vs English } \\
\text { only }\end{array}$ \\
$\begin{array}{ll}\text { Arabic }<.05 \\
\text { +English }\end{array}$ & 33 & $37 \%$ & $\begin{array}{l}\text { Understanding of } \\
\text { scientific concepts as } \\
\text { well as language } \\
\text { enrichment }\end{array}$ & significant \\
\hline English & 17 & $19 \%$ & $\begin{array}{l}\text { Language is learned } \\
\text { with application rather } \\
\text { than evasion }\end{array}$ & \\
\hline
\end{tabular}
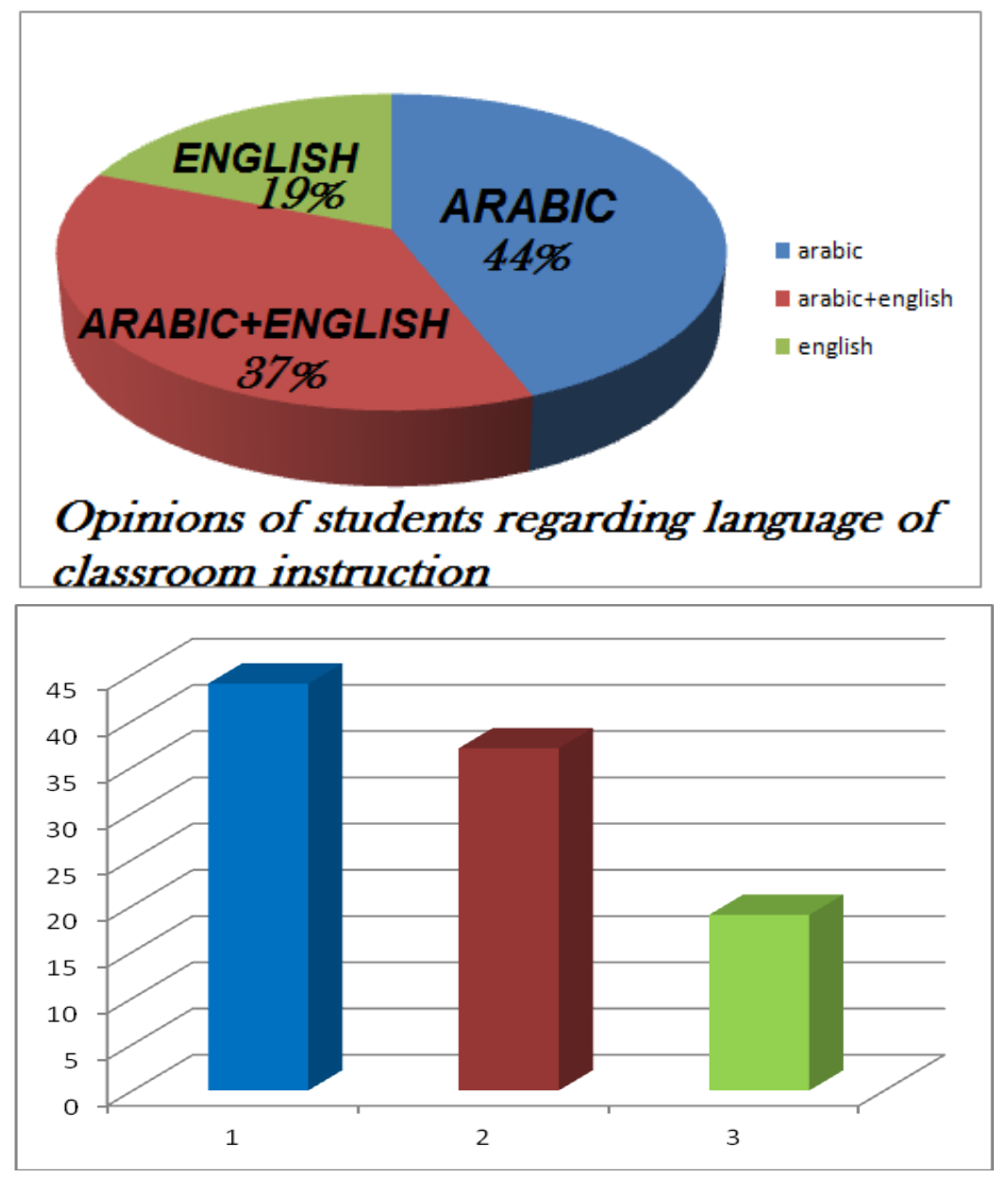

Fig 1- Female students classroom linguistic preferences; N=90, 2nd year, academic session 2010-2011, Pharmacy college, Jazan University, KSA 


\section{DISCUSSION}

'Academic literacy' entails more than the conventional notion of literacy as the ability to read and write. Academic literacy requires the ability to understand how language construes meanings in content-area texts and how meanings and concepts are realized in language -Scheppegrell ;2004. [1]

While there are many factors involved in delivering quality basic education, language is clearly the key to communication and understanding in the classroom. Instruction through a language that learners do not speak has been called "submersion"

[2] because it is analogous to holding learners under water without teaching them how to swim. Such students face difficulties in fully understanding and analyzing concepts, clarifying doubts, expressing themselves in examinations and participating actively in class-room dynamics. This may lead to poor learner involvement, lack of motivation and low confidence levels.

Educational psychology acknowledges the pivotal role of 'spoken language' in the teaching-learning processes; "Communication through verbalization internalizes information". The communication model used during instruction and students/staff perception of the teaching-learning environment can mark the difference between success and failure of an educational program. Communication is an area in which culture can have a significant impact, and it is important for teachers and counselors to understand the Arab's communication styles and preferences in health education for effective assimilation of core knowledge. During the recent past, English has spread as the teaching language in the Arab world in many fields of higher education, thereby prompting a fervent debate about the advantages and disadvantages of studying in English. There are many reasons for dominance of English in Saudi higher education:

The 'one world-one language' myth. Most authorities believe that English is a global language and facilitates expression and exchange of ideas on an international platform)

People believe that local languages cannot express modern concepts. Furthermore, there is scarcity of standard ,high quality text books in Arabic as compared to British authored books .

The 'either-or' myth. It is thought that Bilingualism [Arabic+English] causes confusion and the first language [Arabic] must be pushed aside so that the second language[English] can be learned.

English -the 'high status' language-. People generally believe English to be a symbol of sophistication and affluence. This holds especially true for ex-colonial countries which are still psychologically submerged under the effects of their British rulers.

Many arguments in favor of teaching in a student's mother tongue have been asserted before [3-7]. The use of the native language in teaching is seen as a way to free learners from the linguistic inertia imposed by thinking in one language and studying in another [8].Many countries of the Middle East teach health sciences entirely in English or French; others have certain subjects taught in Arabic, while in Syria, all courses are taught in Arabic [7]. The rationale for continuing to teach in English focuses on the fact that much of the scientific communication, technological advances and academic information in the world is expressed in English [9] and that health science students or doctors attending international conferences, courses or clerkships abroad need to be proficient in the English language in order to express themselves better[10]. However, in 2005, the Arabization Center for Medical Science, together with the deans of numerous health science schools in the Arab world, suggested that learning course content in Arabic does not hinder learners from completing their education abroad or from staying 'in tune' with the modern advances worldwide. [11] The concept of health Arabization does not mean abandoning English altogether; rather the aim is for the students to learn better in their native language while maintaining a good knowledge base of English as the leading language of currant scientific research, as is the case in Japan, Germany, France, Scandinavia and some other European countries.[8] These contradictory schools of thought that exist among the stake holders of the higher education community are prompting educators to explore and identify learning difficulties related to language and possible solutions, if any. Previous studies have addressed this problem of English language for Arab learners.[12] In Saudi Arabia, elementary and primary education is mainly in Arabic, and while some students become proficient in English, others may experience difficulties with language when they progress to higher education where the main mode of instruction entails excessive use of English language and all the prescribed text books are authored by British or American authors, following the pedagogic pattern of contemporary Western universities. Yet, in context of rapid globalization, there are concerns many about accreditation of Saudi institutions, including student qualifications, residency training and continuing education [13]. Published literature states that higher education students are able to differentiate between effective and ineffective teaching methods in lectures. An earlier study showed that students regarded having lectures by properly qualified teachers as particularly important [14].A study in Kuwait, where students

ISSN: $2250-3013$

www.iosrphr.org

$431 \mid \mathrm{P}$ a g e 
evaluated the teaching characteristics of their lecturers stated that well-delivered, organized and logical lectures were the most effective [15]. The results of the Kuwait study are similar to our study and stress the role of language of information delivery as an important aspect in the building of an effective communication model in education. Another similar study in Saudi Arabia emphasized the importance of good lectures and lecturers in encouraging students' attendance at lectures and their understanding and retaining of the information delivered [16] This again corroborates the results of our study in stressing the role of communication in transmission of knowledge.

Therefore, the pedagogical situation in Saudi Arabia is quite paradoxical and interesting; it is almost like a double edged sword. The population of Saudi Arabia is an equal mix of expatriates and native indigenous Saudis. The foreigners working here include Europeans, Pakistanis, Indians, Philipinos, Sudanis, Egyptians and Bangladeshis which account for roughly fifty percent of the country's population. This presents a unique socio-cultural scenario in Higher education, when multi language speakers abound and serve as teachers, administrators, policy makers, technicians, providers etc. As per federal policy on the government front, English is a single foreign language to dominate the higher education sector. On the faculty side, the tutor population is majorly fractioned into Arabic and non-Arabic speakers. When the language of instruction is also foreign to the teacher; as in case of native Arab speaking tutors; there are problems of proper translation and explaining of English text. Conversely, when the tutor is a totally non-Arabic speaking expatriate, there is a major handicap in the form of complete inability in translating English text to Arabic. In both cases; it is difficult for teachers to determine whether students have problems in understanding the concept itself, the language of instruction, or the language of the test and the student has problems in grasping 'what' the teacher or 'text book' means. All said and done, the ultimate sufferers are the students.

In such a diabolical situation, choosing the middle path; a bilingual approach is recommended. Bilingual instruction allows teachers and students to interact naturally and negotiate meanings together, creating participatory learning environments that are conducive to cognitive as well as affective development. [17-20] Student learning can be accurately assessed in bilingual classrooms. When students can express themselves, teachers can diagnose what has been learned, what remains to be taught and which students need further assistance. However, adopting such a hybrid approach might not be as easy as it may seem. Main barriers to the bi-lingual approach lie in policy development \& implementation of bilingual programs; developing effective bilingual academic materials and training faculty /staff for a structured bi-lingual instructional strategy.

\section{CONCLUSION}

Despite modern curricular and instructional innovations, a majority of Arab health science students still prefer their mother tongue as the predominant medium of classroom instruction. The key underlining factor for such attitudes is the harmony between 'thinking and speaking' that is created with the use of "familiar" language. English is not a "superior", but a "more common" language of the world. Language handicap often bars brilliant students from satisfactory performance during assessments. Proficiency in English can facilitate effective clinical communication at indigenous and international platforms. Societal attitudes and home environments should be developed as resources to contribute towards better learner acceptance and motivation in nations where English is a foreign language. While the pedagogic implications of 'language' of instruction need further exploration; collaboration between teachers and peers and informative media development can reduce the distance between expectations and performance for Non-English-speaking nations like Saudi Arabia. 


\section{REFERENCES}

[1]. Schleppegrell J, Aghugar M \& Oteiza T. The grammar of History: Enhancing con ten t-based instruction through a function al focus on language. TESOL Quarterly, 38, 2004,67-93.

[2]. $\quad$ Skutnabb-Kangas, T. Linguistic Genocide in Education—or Worldwide Diversity and Human Rights? Mahwah NJ: Lawrence Erlbaum. 2000

[3]. Drouin J. Educating future physicians for a minority population: a French-language stream at the University of Ottawa. Academic Medicine, 2002, 77(3):217-221.

[4]. Haidinger G, Frischenschlager O, Mitterauer L. Reliability of predictors of study success in medicine. Wiener Medizinische Wochenschrift, 2006, 156(13-14):416-420.

[5]. Khayat MH. مد تطرد حدي ث :الـ تعري ب [Arabization: A continuous conversation]. Medical Arabization, 2002, 6(1):62-67.

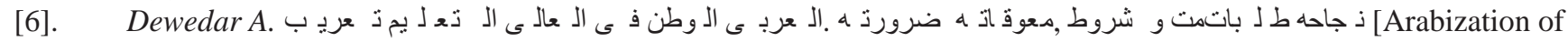
higher education in the Arab world. Necessity, obstacles, conditions and requirements of success]. 85 - 271: 43 ؛ 2004 [Journal of the Association of Arab Universities, 2004, 43:271-285].

[7]. Al-Kateb B, Review of the history of the teaching of medicine in Arabic. Eastern Mediterranean Health Journal, 1999, 5(3):597-603.

[8]. Ali EA. The language of scientific research. IslamOnline [online article] (http://www.islamonline.net/servlet/Satellite?c=Article_C\&cid=1158658285017\&pagename=Zone-EnglishHealthScience\%2FHSELayout, accessed 29 June 2010).

[9]. Maher J. The development of English as an international language of medicine. Applied Linguistics, 1986, 7(2):206218.

[10]. Kassem AM. Learning English makes sense. Student British Medical Journal, 2004, 12:133-176.

[11]. El-Awady NA. Arabized medicine moves one step forward. Islam- Online [online article] (http://www.islamonline.net/English/Science/2005/04/article06.shtml, accessed 29 June 2010).

[12]. Manzar S. The English language and Arabic medical students. Medical Education, 1999, 33(5):394-395.

[13]. Conaboy KA et al. Central Asian Republics: a case study for medical education reform. Journal of Continuing Education in the Health Professions, 2005, 25(1):52-64.

[14]. Weber A et al. Ausbildungs- und Berufserwartungen der Arztegeneration von morgen [Educational and occupational expectations of tomorrow's generation of physicians]. Gesundheitswesen, 1996, 58(12):629-634.

[15]. Fido A, Al-Kazemi R. Effective method of teaching psychiatry to undergraduate medical students: the student perspective. Medical Principles and Practice, 2000, 9:255-259.

[16]. Milaat WA, El-Gamal FM . Factors affecting the use and attitude towards medical resources and educational methods in a Saudi medical school. Annals of Saudi Medicine, 1994, 14(3):209-214

[17]. Adegbija, E. 2003 Central language issues in literacy and basic education: Three mother tongue education experiments in Nigeria. In Ouane, A. (ed), 167-182.

[18]. Akinnaso, F. 1993 Policy and experiment in mother tongue literacy in Nigeria. International Review of Education 43:1.

[19]. Fafunwa, A., Macauley, J. \& Soyinka, J. (eds) (1989) Education in Mother Tongue. The Ife Primary Education Research Project (1970-1978). Ibadan: University Press.

[20]. Modiano, N. 1973 Indian Education in the Chiapas Highlands. New York: Holt, Rinehart \& Winston. 